\title{
Primary adrenal teratoma: A case series and review of the literature
}

\author{
LIANG ZHOU ${ }^{1,2^{*}}$, XIANG PAN ${ }^{2,3 *}$, TAO HE ${ }^{2}$, YULIN LAI $^{2}$, WENHUA LI ${ }^{2}$, YIMING HU ${ }^{2}$, \\ LIANGCHAO NI ${ }^{2}$, SHANGQI YANG ${ }^{2}, \mathrm{YUN} \mathrm{CHEN}^{4}$ and YONGQING LAI ${ }^{2}$
}

${ }^{1}$ Department of Urology, Guangzhou Medical University, Guangzhou, Guangdong 511436; ${ }^{2}$ Department of Urology, Peking University Shenzhen Hospital, Shenzhen, Guangdong 518036; ${ }^{3}$ Department of Urology, Anhui Medical University, Hefei, Anhui 230032; ${ }^{4}$ Department of Ultrasound, Peking University Shenzhen Hospital, Shenzhen, Guangdong 518036, P.R. China

Received October 17, 2017; Accepted May 3, 2018

DOI: $10.3892 / \mathrm{mco} .2018 .1687$

\begin{abstract}
Primary adrenal teratoma is a rare type of cancer. Of the 338 patients who underwent adrenalectomy during this study, only 2 (aged 69 and 29 years) were diagnosed with adrenal teratoma and underwent laparoscopic retroperitoneal adrenalectomy. For the purposes of the present study, the term 'adrenal teratoma' was searched in the PubMed database, and 237 articles published between June 1952 and March 2017 were retrieved. However, we were only able to identify 10 relevant studies. In total, these studies reported a series of 18 cases of primary adrenal teratoma in patients aged $>16$ years, another 8 cases of adult adrenal retroperitoneal teratoma, and 7 cases of adrenal teratoma in children aged $<16$ years. In the 18 cases aged $>16$ years, the age range was 17-61 years (mean \pm standard deviation, $33.06 \pm 15.47$ years), the median tumor diameter was $8.25 \mathrm{~cm}$ and 13 patients $(72.22 \%)$ were female. Almost all patients underwent laparoscopic surgery between 2006 and 2017 (75\%). Among the 7 cases of adrenal teratoma in children under the age of 16 years, 5 cases $(71.43 \%$ ) were male, the median tumor diameter was $10 \mathrm{~cm}$, the oldest patient was aged 8 years, 5 cases $(71.43 \%)$ were selected for open surgical resection of the tumor, and 5 cases $(71.43 \%)$ were followed up without recurrence or death. These data indicate that primary adrenal teratomas in children are rarer compared with adults. Although the data are limited, it was observed that the clinical symptoms of primary adrenal teratoma are not typical, the
\end{abstract}

Correspondence to: Professor Yongqing Lai, Department of Urology, Peking University Shenzhen Hospital, 1120 Lianhua Road, Shenzhen, Guangdong 518036, P.R. China

E-mail: yqlord@163.com

Professor Yun Chen, Department of Ultrasound, Peking University Shenzhen Hospital, Shenzhen, 1120 Lianhua Road, Guangdong 518036, P.R. China

E-mail: cyun126@126.com

*Contributed equally

Key words: adrenal, teratoma, retroperitoneal, adult, children preferred treatment is retroperitoneal laparoscopic surgery, and the prognosis is favorable. The aim of the present study was to elucidate the clinical characteristics associated with primary adrenal teratoma, in order to further raise awareness of this rare disease.

\section{Introduction}

Teratoma is a type of germ cell tumor, originating from pluripotent cells with multi-directional potential of differentiation into different types of somatic cells. The majority of teratomas contain more than one embryonic germ cell layer, mostly elements derived from ectoderm and least frequently from endoderm; therefore, teratomas may contain skin, hair, teeth, brain tissue, nerves, adipose tissue and cartilage, among others (1). Teratoma presenting outside the gonads is rare, while adrenal teratomas are even rarer. Teratomas are divided into mature and immature, according to the degree of tissue differentiation. Mature teratomas are benign, with a low malignant potential, although they may develop malignant transformation (2). Primary retroperitoneal teratomas are uncommon in patients aged $>30$ years, with only $10.0 \%$ of reported cases being over that age (3). The PubMed database was searched for the term 'adrenal teratoma', and 239 articles published between June 1952 and April 2017 were identified; however, only 10 of those articles were considered relevant to the present study. In total, these studies reported or described 18 cases of adult patients with primary adrenal teratomas (Table I), 7 cases of adrenal teratoma in children aged $<16$ years (Table II), and 8 cases of retroperitoneal teratoma of the adrenal gland (Table III). The purpose of this study was to review our experience with diagnosis and treatment of primary adrenal teratoma, in order to determine the clinical characteristics associated with this rare tumor.

\section{Case reports}

Case 1. A mass in the left abdomen developing for 3 months was identified in a 69-year-old female patient who was admitted to the hospital for further examination and treatment. No other physical findings were observed. Computed tomography (CT) examination after admission revealed a spindle-shaped mass 
Table I. Cases of adult primary adrenal teratoma reported in the literature.

\begin{tabular}{|c|c|c|c|c|c|c|c|c|c|}
\hline Case & Age (years) & Year & Sex & Presentation & Location & Size $(\mathrm{cm})$ & Surgery & $\begin{array}{c}\text { Follow-up } \\
\text { (months) }\end{array}$ & (Refs.) \\
\hline 1 & 17 & 1987 & M & Pain & Left & 8.0 & NA & NA & (4) \\
\hline 2 & 18 & 1999 & $\mathrm{~F}$ & Back pain & Left & $11 \times 8 \times 7$ & NA & NA & (5) \\
\hline 3 & 17 & 1999 & M & Back pain for 2 months & Right & $7.5 \times 6 \times 3$ & NA & NA & $(5)$ \\
\hline 4 & 37 & 1999 & $\mathrm{~F}$ & Back pain for 1 year & Left & 10 & NA & NA & $(5)$ \\
\hline 5 & 57 & 2002 & $\mathrm{~F}$ & Abdominal pain for 6 months & Left & $8.0 \times 7.0 \times 5.0$ & NA & NA & (3) \\
\hline 6 & 21 & 2004 & $\mathrm{~F}$ & Increased abdominal mass & Left & $38 \times 30 \times 30$ & NA & NA & (6) \\
\hline 7 & 61 & 2006 & $\mathrm{~F}$ & Incidental discovery & Left & 8.0 & Laparoscopic & 12 & (7) \\
\hline 8 & 40 & 2010 & $\mathrm{~F}$ & Pain & Right & $9 \times 8 \times 5$ & Open & NA & (8) \\
\hline 9 & 49 & 2015 & M & Incidental discovery & Right & $6.0 \times 7.0 \times 11$ & Retroperitoneoscopic & 8 & (9) \\
\hline 10 & 21 & 2015 & $\mathrm{~F}$ & Incidental discovery & Right & 8.5 & Retroperitoneoscopic & $4-60$ & $(10)$ \\
\hline 11 & 16 & 2015 & $\mathrm{~F}$ & Incidental discovery & Right & 9.0 & Retroperitoneoscopic & $4-60$ & $(10)$ \\
\hline 12 & 43 & 2015 & $\mathrm{~F}$ & Incidental discovery & Left & 4.9 & Retroperitoneoscopic & $4-60$ & $(10)$ \\
\hline 13 & 49 & 2015 & $\mathrm{~F}$ & Incidental discovery & Left & 5.3 & Retroperitoneoscopic & $4-60$ & $(10)$ \\
\hline 14 & 51 & 2015 & $\mathrm{~F}$ & Incidental discovery & Right & 2.4 & Retroperitoneoscopic & $4-60$ & $(10)$ \\
\hline 15 & 19 & 2015 & M & Flank pain for 9 months & Right & $8 \times 6 \times 4$ & Open & 12 & (11) \\
\hline 16 & 26 & 2017 & M & Flank pain & Right & $8.5 \times 5.5 \times 4.8$ & Open & NA & (12) \\
\hline 17 & 29 & 2017 & $\mathrm{~F}$ & Incidental discovery & Left & $2.5 \times 2.1 \times 0.5$ & Laparoscopic & NA & (12) \\
\hline 18 & 24 & 2017 & $\mathrm{~F}$ & Abdominal pain & Left & $11.5 \times 9.0 \times 3$ & Laparoscopic & NA & (12) \\
\hline
\end{tabular}

M, male; F, female; NA, not available.

Table II. Pediatric cases of adrenal teratoma reported in the literature.

\begin{tabular}{|c|c|c|c|c|c|c|c|c|c|}
\hline Case & Age & Year & Sex & Presentation & Location & Size $(\mathrm{cm})$ & Surgery & $\begin{array}{c}\text { Follow-up } \\
\text { (months) }\end{array}$ & (Refs.) \\
\hline 1 & 5 years & 1968 & M & Incidental discovery & Right & $10 \times 7.5 \times 3.5$ & Open & 6 & (13) \\
\hline 2 & 8 years & 2006 & M & Lumbar pain after a fall & Right & 8.0 & Laparoscopic & 3 & (7) \\
\hline 3 & 45 days & 2009 & M & Incidental discovery & Left & $5.5 \times 4.5 \times 3$ & Open & 12 & (14) \\
\hline 4 & 4 years & 2011 & $\mathrm{~F}$ & Incidental discovery & Left & 3.0 & Open & 13 & $(15)$ \\
\hline 5 & 8 years & 2011 & $\mathrm{M}$ & Abdominal pain & Right & $10 \times 8 \times 6$ & Open & 6 & $(16)$ \\
\hline 6 & 3 months & 2013 & M & Abdominal distension & Left & $14 \times 10 \times 8$ & NA & NA & $(17)$ \\
\hline 7 & 3 months & 2017 & $\mathrm{~F}$ & Abdominal distention & Right & $10 \times 10 \times 8$ & Open & NA & (18) \\
\hline
\end{tabular}

M, male; F, female; NA, not available.

of heterogeneous density in the left adrenal gland, consisting mainly of fat tissue; a small number of calcifications and soft tissue density shadows were visible. The mass was sized $\sim 9.3 \times 4.9 \mathrm{~cm}$ (Fig. 1). The results of complete blood counts and routine biochemical assessment, including kidney and liver function tests, revealed no major abnormalities. The test results for serum cortisol, adrenocorticotropic hormone, renin-angiotensin-aldosterone, plasma epinephrine, plasma norepinephrine, plasma dopamine and urinary vanillylmandelic acid were unremarkable. Therefore, the clinical diagnosis was left adrenal mass. Subsequent retroperitoneal left adrenal lumpectomy was successfully performed. After the tumor was completely removed, gross postoperative examination revealed a grayish-yellow mass, sized $10.0 \times 6.0 \times 4.0 \mathrm{~cm}$, including visible gray cartilage tissue and bone-like hard tissue. Hematoxylin and eosin (H\&E) staining was conducted as follows: The tissue was fixed using a $10 \%$ formalin solution at $37^{\circ} \mathrm{C}$ for $24 \mathrm{~h}$. Sections were cut to $6-8 \mu \mathrm{m}$ thickness then dried in an incubator at $45^{\circ} \mathrm{C}$. Subsequently, sections were stained with hematoxylin for $15 \mathrm{~min}\left(37^{\circ} \mathrm{C}\right)$, rinsed under running water for $1 \mathrm{~min}$ then left standing in water for $5 \mathrm{~min}$. Staining with $0.5 \%$ eosin was also conducted for $3 \mathrm{~min}\left(37^{\circ} \mathrm{C}\right)$, followed by a rinse under running water. Under examination with an optical microscope, the tumor included adipose tissue, cartilage, calcification, ossification and smooth muscle. Tubular structures with stratified epithelium, with no obvious mitotic figures, were regionally identified, and were surrounded by fiber and smooth muscle. The tumor 
Table III. Cases of retroperitoneal adrenal teratoma reported in the literature.

\begin{tabular}{|c|c|c|c|c|c|c|c|c|c|}
\hline Case & Age (years) & Year & Sex & Presentation & Location & Size $(\mathrm{cm})$ & Surgery & $\begin{array}{l}\text { Follow-up } \\
\text { (months) }\end{array}$ & (Refs.) \\
\hline 1 & 33 & 2007 & M & Incidental discovery & Left & $9 \times 7 \times 5$ & Open & 18 & (19) \\
\hline 2 & 37 & 2010 & $\mathrm{M}$ & Accidental discovery & Left & $20 \times 14 \times 13$ & Laparoscopic & 4 & $(20)$ \\
\hline 3 & 50 & 2011 & $\mathrm{~F}$ & Back pain for 2 years & Left & $8 \times 4 \times 3.5$ & Laparoscopic & 18 & $(21)$ \\
\hline 4 & 62 & 2011 & $\mathrm{M}$ & Incidental discovery & Left & $4.7 \times 3.0$ & Laparoscopic & 48 & $(22)$ \\
\hline 5 & 22 & 2013 & M & Flank pain for 1 month & Left & $9.0 \times 9.0 \times 10$ & NA & 6 & (23) \\
\hline 6 & 39 & 2014 & $\mathrm{~F}$ & Dizziness for 6 months & Right & $22.5 \times 17 \times 7$ & NA & 18 & (24) \\
\hline 7 & 24 & 2016 & $\mathrm{~F}$ & Pain and coughing for 2 years & Left & $7.6 \times 3 \times 6.5$ & NA & NA & $(25)$ \\
\hline 8 & 32 & 2016 & $\mathrm{~F}$ & Incidental discovery & Right & $5.1 \times 3.6 \times 3.4$ & Retroperitoneoscopic & 29 & $(26)$ \\
\hline
\end{tabular}

M, male; F, female; NA, not available.

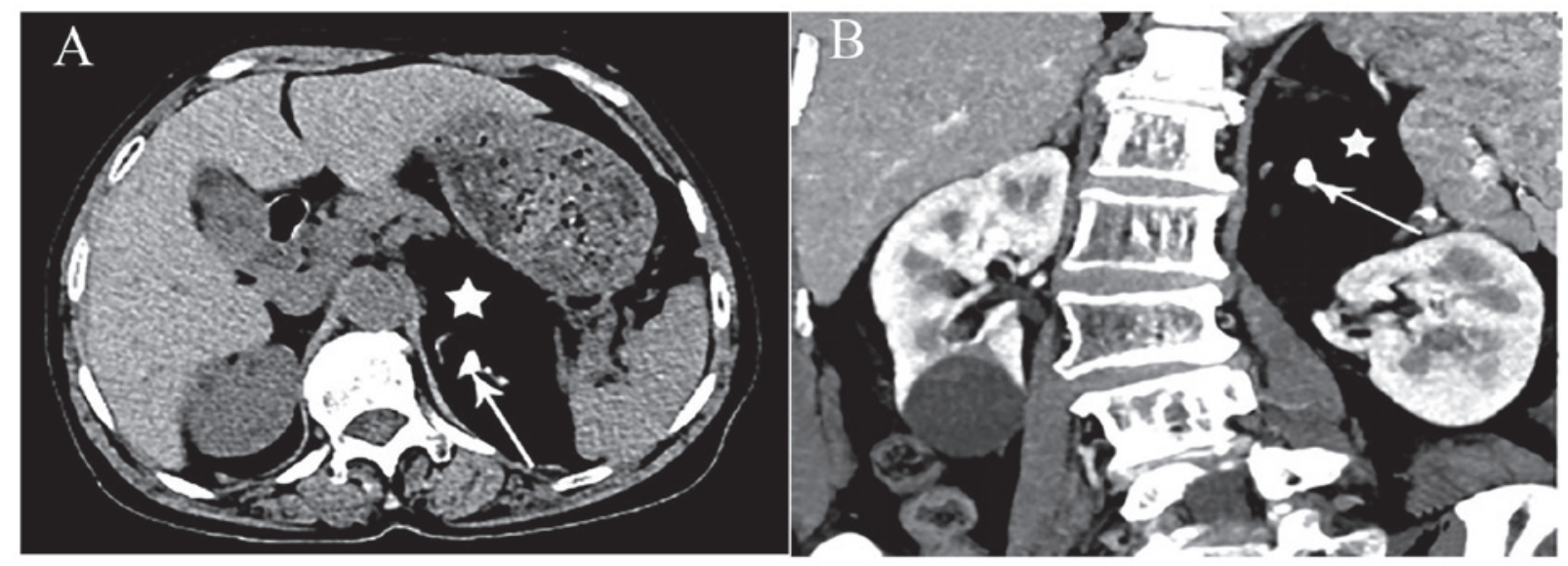

Figure 1. (A) Axial plain computed tomography (CT) scan and (B) coronal enhanced CT scan showing a heterogeneous mass in the left adrenal gland with calcification (arrow) and a fatty tissue component (asterisk).

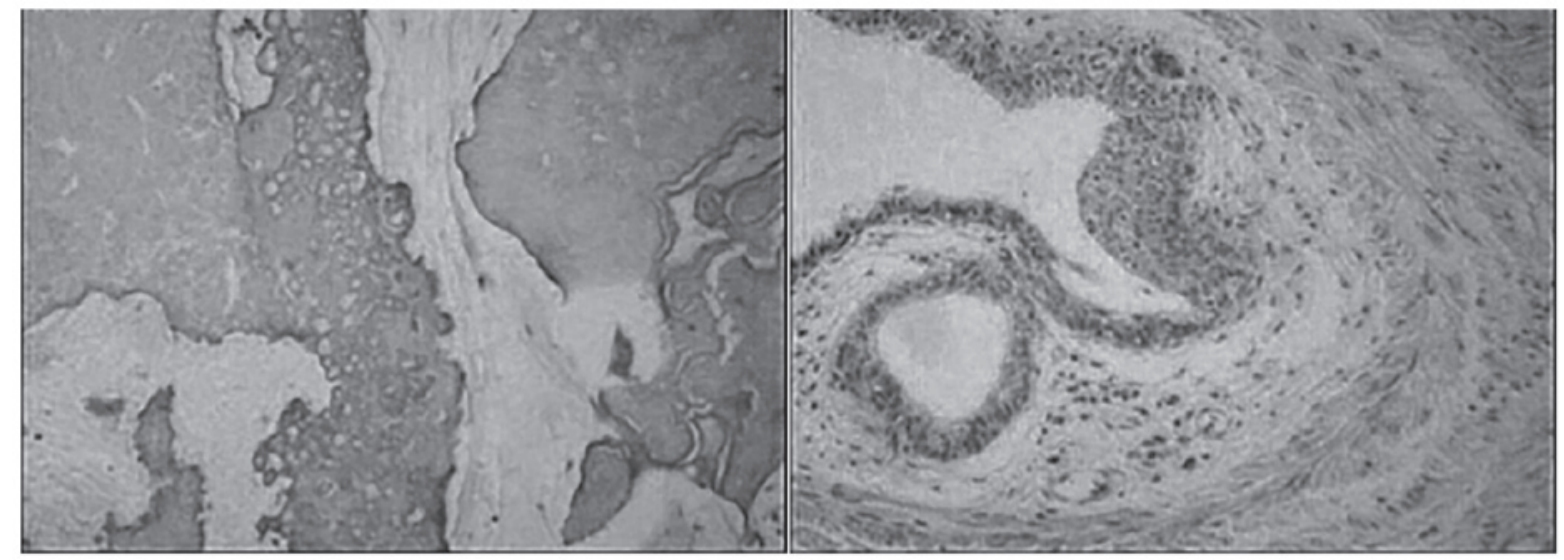

Figure 2. Microscopy revealed tubules or small capsular structures of tumor lining ciliated columnar epithelium or flattened epithelium [hematoxylin and eosin (H\&E) staining; left panel, magnification, x400]. Microscopy revealed that the tumor local vascular rich and inflammatory cell infiltration (H\&E staining; right panel, magnification, $\mathrm{x} 400)$.

was infiltrated by inflammatory cells, and included scattered tubular and vesicular structures lined by ciliated columnar epithelium or flattened epithelium (Fig. 2). Based on these findings, the pathological analysis of the specimens from the left adrenal gland suggested the diagnosis of teratoma. The patient was stable, did not complain of pain postoperatively, and exhibited no recurrence at the 1-year follow-up.

Case 2. An asymptomatic 29-year-old woman was admitted to the hospital due to incidental discovery of a left adrenal mass 
1 month prior. A CT examination after admission revealed an irregular pelvic lesion, sized $6.0 \times 4.0 \mathrm{~cm}$, in the lower part of the left adrenal gland (Fig. 3). Calcification was identified at the edge of the tumor. Routine blood examinations, such as liver and kidney function tests, electrolytes and other routine tests, revealed no major abnormalities. Plasma adrenal-associated hormone levels, adrenocorticotropic hormone, renin activity, angiotensin, aldosterone, cortisol, and urine vanillylmandelic acid levels were within the normal range. Thus, the clinical diagnosis was left adrenal gland mass. Subsequently, complete laparoscopic retroperitoneal adrenalectomy was successfully performed. Macroscopic examination of the sample revealed a grayish-red mass, sized $2.5 \times 2.1 \times 0.5 \mathrm{~cm}$, of mixed consistency. The capsule of the mass was gray and solid. H\&E staining was conducted as aforementioned. Microscopic examination revealed a tumor cyst wall lined with squamous epithelium, and cartilage was also identified (Fig. 4). Based on these findings, the pathological analysis of the specimens from the left adrenal gland suggested the diagnosis of mature teratoma. The patient was stable postoperatively and no recurrence had occurred at the 12-month follow-up.

\section{Results}

A total of 18 cases of definitive adult primary adrenal teratomain patients aged 17-61 years [mean \pm standard deviation (SD); $33.06 \pm 15.47$ years] were identified in the literature. Of the 18 patients, 13 were female (72.22\%). A total of 8 patients $(44.44 \%)$ visited a doctor after they incidentally found an adrenal mass, and 7 patients (38.89\%) visited a doctor due to abdominal or back pain. Of the 18 patients, $9(50 \%)$ experienced pain, and teratoma was found in the left adrenal gland in 9 patients (50\%). The median diameter of the tumor was $8.25 \mathrm{~cm}$. The majority of the patients consented to laparoscopic surgery between 2006 and 2017 (75\%). Definitive follow-up data suggesting a good prognosis were only reported for8 of the cases $(44.44 \%)$.

Among patients aged $<16$ years, 7 pediatric cases of adrenal teratoma were reported in the literature, of whom were 5 male $(71.43 \%)$. A total of 3 cases $(42.86 \%)$ were incidentally found during examination, 2 cases $(28.57 \%)$ visited a doctor due to pain, and 2 cases $(28.57 \%$ ) visited a doctor due to abdominal distension. The median tumor diameter was $10 \mathrm{~cm}$. The oldest pediatric patient was aged 8 years. Only 1 patient underwent laparoscopic tumor resection, and there was no reported disease recurrence or death during the follow-up period in 5 patients.

Due to the rarity of teratoma, there is no clear clinical or pathological definition for this condition (3). It remains to be determined whether primary adrenal teratoma should be considered as a pathological entity similar to other retroperitoneal teratomas. According to its definition, primary retroperitoneal teratoma is not specific to any organ, and is most common in the left adrenal region. The present research also identified 8 cases of adult adrenal gland retroperitoneal teratomas ( 4 male and 4 female patients). These patients were aged 24-62 years (mean \pm SD; 37.38 \pm 13.27 years). Four of the patients were admitted to the hospital due toan incidentally discoveredadrenal mass, and in 6 cases $(75 \%)$ the mass was located in the left adrenal gland. The median tumor diameter was $8.5 \mathrm{~cm}$. The tumors were successfully removed laparoscopicallyin 4 cases (50\%). Complete follow-up data were available for 7 cases $(87.5 \%)$, and they all had a good prognosis. There was 1 reported death due to hypertension (24).

\section{Discussion}

Adrenal mature teratomas are generally non-functional, and the tumor exhibits latent growth. During the early stages, the tumor causes no signs or symptoms. Later, as the tumor increases in size, it may press on the surrounding organs, which may cause abdominal discomfort and distension, lumbago, back pain, nausea, vomiting, weight loss, urinary retention, intestinal obstruction, even swelling of the lower extremity or genitals due to lymphatic obstruction. There is no specificity regarding the organs affected by this tumor or the symptoms. For example, when a cystic teratoma ruptures, patients may suddenly experience abdominal pain, peritoneal effusion or peritonitis (1), while other patients remain asymptomatic (2).

B-scan ultrasound, CT and magnetic resonance imaging (MRI) can clearly demonstrate the location, shap, and anatomical associations of the tumor. Tumors on B-scan appear as a heterogeneous group of strong light signals and contained a variety of cystic/solid elements with uneven echo, reflecting the tumor tissue composition. However, this qualitative diagnosis is not sufficient. The appearance of teratoma on CT is quite characteristic, and its diagnostic accuracy is superior to that with B-ultrasound. CT images of mature teratoma reveal the presence of calcification and adipose tissue, the growth site of the tumor is clear, the capsule is continuous with the surrounding tissues and organs, and the presence of infiltration and invasive growth can be determined. This level of clarity is useful for providing the basis for preoperative assessment and selection of the surgical method (27). MRI can demonstrate the internal characteristics of the tumor and the location of tumor blood vessels, improve the resolution of soft tissue, clearly delineate the border between the tumor capsule and the surrounding adipose tissue, and determine the association between the teratoma and major blood vessels and the presence of infiltration (1). Therefore, the results of preoperative imaging and postoperative pathology are crucial for the final diagnosis of teratoma.

Adrenal teratoma is usually treated by surgical resection. The goal is complete removal of the tumor without damaging adjacent tissues and organs, in order to relieve the clinical symptoms and prevent malignant transformation (28). In addition, if the tumor can be completely resected, a biopsy is not considered necessary. Teratomas are not sensitive to radiotherapy or chemotherapy. The surgical procedure is complicated, as adrenal mature teratoma is often closely associated or wrapped around important blood vessels with thin walls; this makes complete resection exceedingly difficult. If necessary, the complicating blood vessels should be severed and then ligated. In general, mature teratoma exhibits a high degree of tissue differentiation (29). Complete resection is usually curative, with only few reported cases of recurrence and metastasis (30). A completely resected benign teratoma may not require adjuvant chemotherapy, as it has been reported that mature adrenal teratomas have been successfully resected in patients as young as 8 and as old as61 years. Both patients recovered well, with no recurrence (7). 

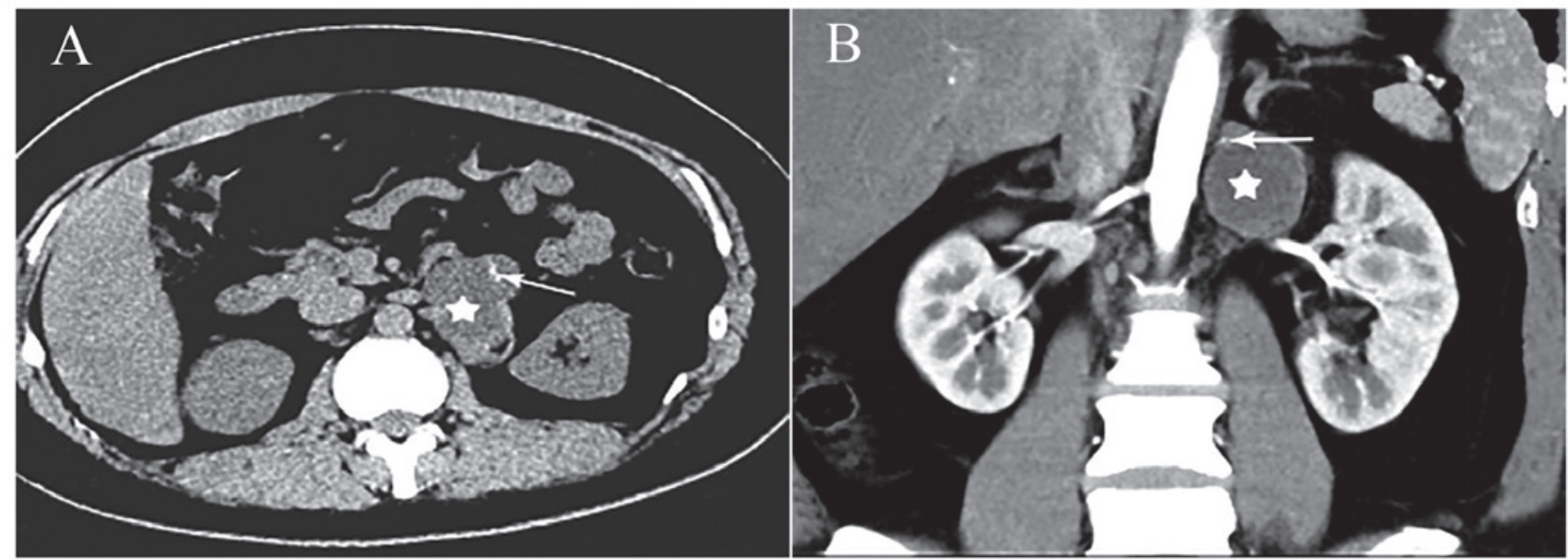

Figure 3. (A) Axial plain computed tomography (CT) scan and (B) coronal enhanced CT scan showing a punctate calcification (arrow) at the edge of anirregular left adrenal mass (asterisk).

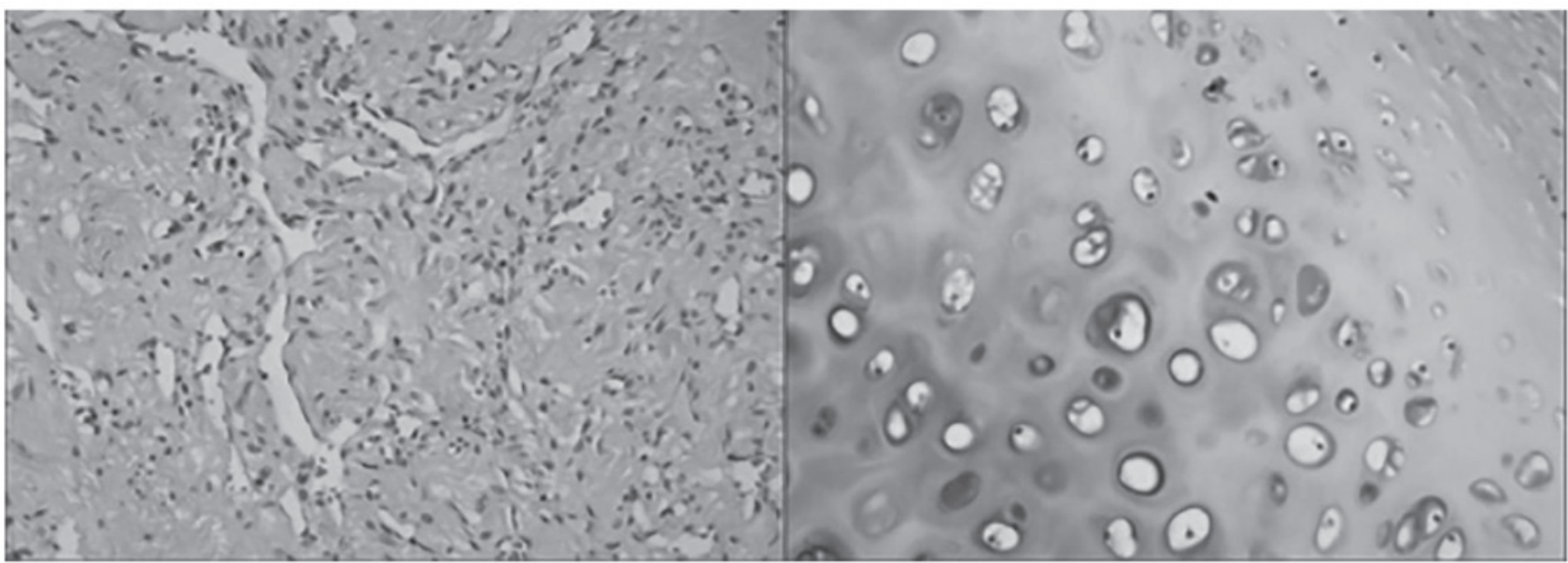

Figure 4.Microscopic examination revealed the cyst wall waslined with squamous epithelial cells[hematoxylin and eosin (H\&E) staining; left panel, magnification, $\mathrm{x} 100]$ and the cartilage (H\&E staining; right panel, magnification, $\mathrm{x} 400$ ).

At present, laparoscopic surgery remains the primary choice for the treatment of adrenal tumors. Laparoscopic techniques have been used in adrenal surgery since 1992, have developed rapidly and are increasingly being used in urology (31). Due to the small incision and fast recovery, laparoscopic surgery has become the preferred treatment method for mature adrenal teratomas. Laparoscopic surgery is currently the gold standard for the removal of adrenal lesions (32).

Pediatric adrenal teratomas are uncommon, representing $5 \%$ of all pediatric teratomas (12). Although pediatric cases of adrenal teratomas have not been found in our literature review, primary adrenal teratomas have been reported in neonates, infants and children. Interestingly, primary adrenal teratoma has been reported to have a maximum onset age of 8 years, with no reports in the literature of such tumors in older children.

In conclusion, primary adrenal teratoma is a rare tumor, which is more common in adults compared with children. Adult primary adrenal teratoma occurs more often in men; however, among pediatric cases, there were more female compared with male patients. In both adults and children, adrenal primary adrenal teratoma usually manifests as a large adrenal mass, preoperative diagnosis is difficult, and diagnosis can only be confirmed by histopathological examination following surgical removal of the tumor. Laparoscopic surgery is the primary treatment choice for adult adrenal teratoma, but children with primary adrenal teratoma usually undergo open surgery. Based on the available follow-up data, adults and children with primary adrenal teratoma have a good prognosis with treatment. Due to the limited number of cases reported in the literature, the current results are not comprehensive. More studies and clinical cases of teratoma with long-term follow-up data must be published and analyzed to confirm these trends.

\section{Acknowledgements}

Not applicable.

\section{Funding}

The present study was supported by the National Natural Science Foundation of China (grant no. 81101922), Science 
and Technology Development Fund Project of Shenzhen (grant nos. JCYJ20160429090753103 and JCYJ20170307111334308), the fund of 'San-ming' Project of Medicine in Shenzhen (grant no. SZSM201612066), the Fund of Shenzhen Key Laboratory (grant no. ZDSYS201504301045406) and the fund of Guangdong Key Medical Subject.

\section{Availability of data and materials}

The analyzed data sets generated during the study are available from the corresponding author on reasonable request.

\section{Authors' contributions}

LZ and XP performed the experimental work, data collection and interpretation. TH and YL participated in the design and coordination of experimental work, and acquisition of data. WL, YH, LN and SY participated in the study design, data collection, analysis of data and preparation of the manuscript. YL conducted the study design, the analysis and interpretation of data and drafted the manuscript. All authors read and approved the final manuscript.

\section{Ethics approval and consent to participate}

Consent to participate was obtained from all patients.

\section{Consent for publication}

Consent for publication of any associated data and accompanying images was obtained from all patients.

\section{Competing interests}

The authors declare that they have no competing interests.

\section{References}

1. Scott AL, Abbassi-Ghadi N, Archer CM, Swamy R and Gupta S Neuroendocrine carcinoma arising within a retroperitoneal mature teratoma. Ann R Coll Surg Engl 92: W5-W8, 2010.

2. Gatcombe HG, Assikis V, Kooby D and Johnstone PA: Primary retroperitoneal teratomas: A review of the literature. J Surg Oncol 86: 107-113, 2004

3. Bedri S, Erfanian K, Schwaitzberg S and Tischler AS: Mature cystic teratoma involving adrenal gland. Endocr Pathol 13: 59-64, 2002.

4. McMillan A and Horwich A: Malignant teratoma presenting with an adrenal mass. Clin Radiol 38: 327-328, 1987.

5. Lam KY and Lo CY: Teratoma in the region of adrenal gland: A unique entity masquerading as lipomatous adrenal tumor Surgery 126: 90-94, 1999.

6. Polo JL, Villarejo PJ, Molina M, Yuste P, Menéndez JM, Babé J and Puente S: Giant mature cystic teratoma of the adrenal region. AJR Am J Roentgenol 183: 837-838, 2004

7. Castillo OA, Vitagliano G, Villeta M, Arellano L and Santis O: Laparoscopic resection of adrenal teratoma. JSLS 10: 522-524, 2006.

8. Shrestha MK and Lalchan S: Adrenal gland teratoma in a 40-year-old woman. Nepal Med Coll J 12: 201-202, 2010.

9. Li H, Zhao T, Wei Q, Yuan H, Cao D, Shen P, Liu L, Zeng H and Chen N: Laparoscopic resection of a huge mature cystic teratoma of the right adrenal gland through retroperitoneal approach: A case report and literature review. World J Surg Oncol 13: 318 , 2015 .
10. Li S, Li H, Ji Z, Yan W and Zhang Y: Primary adrenal teratoma: Clinical characteristics and retroperitoneal laparoscopic resection in five adults. Oncol Lett 10: 2865-2870, 2015.

11. Nadeem M, Ather MH, Sulaiman MN and Pervez S: 'Looks Can Be Deceiving': Adrenal Teratoma Causing Diagnostic Difficulty. Case Rep Urol 2015: 232591, 2015.

12. Kuo EJ, Sisk AE, Yang Z, Huang J, Yeh MW and Livhits MJ: Adrenal Teratoma: A Case Series and Review of the Literature. Endocr Pathol 28: 152-158, 2017.

13. Engel RM, Elkins RC and Fletcher BD: Retroperitoneal teratoma. Review of the literature and presentation of an unusual case. Cancer 22: 1068-1073, 1968.

14. Oguzkurt P, Ince E, Temiz A, Demir S, Akabolat F and Hicsonmez A: Prenatal diagnosis of a mass in the adrenal region that proved to be a teratoma. J Pediatr Hematol Oncol 31: 350-351, 2009.

15. Li Y, Zhong Z and Zhao X: Primary mature teratoma presenting as an adrenal tumor in a child. Urology 78: 689-691,2011.

16. Ersoz S, Kucuk H, Mungan S, Turgutalp H, Imamoglu M and Kosucu P: Neurocytoma arising in an adrenal gland mature teratoma. Fetal Pediatr Pathol 30: 275-279, 2011.

17. Ciftci I, Cihan T, Koksal Y, Ugras S and Erol C: Giant mature adrenal cystic teratoma in an infant. Acta Inform Med 21: 140-141, 2013.

18. Garg A, Pollak-Christian E and Unnikrishnan N: A Rare Adrenal Mass in a 3-Month-Old: A Case Report and Literature Review. Case Rep Pediatr 2017: 4542321, 2017.

19. Rais-Bahrami S, Varkarakis IM, Lujan G and Jarrett TW: Primary retroperitoneal teratoma presenting as an adrenal tumor in an adult. Urology 69: 185 e181-e182, 2007.

20. Sato F, Mimata H and Mori K: Primary retroperitoneal mature cystic teratoma presenting as an adrenal tumor in an adult. Int J Urol 17: 817, 2010.

21. Chen JC, Khiyami A and McHenry CR: Retroperitoneal cystic teratoma masquerading as an incidentally discovered adrenal mass. Endocr Pract 17: e130-e134, 2011.

22. Giordano R, Giraudo G, Forno D, Bosco M, Delsedime L, Morino M and Arvat E: A case of primary retroperitoneal teratoma presenting as an adrenal incidentaloma. J Endocrinol Invest 34: 645-646, 2011.

23. Bhatti A, Al-Hindi H, Azzam A, Amin T and Abu-Zaid A: Mature (benign) cystic retroperitoneal teratoma involving the left adrenal gland in a 22-year-old male: A case report and literature review. Case Rep Oncol Med 2013: 610280, 2013.

24. Tang DD, Zhang XS, Hao ZY, Zhou J and Liang CZ: A giant primary retroperitoneal mature cystic teratoma in right adrenal region in a 39-year-old female. Int J Clin Exp Med 7: 1611-1613, 2014.

25. Bhatia V, Sharma S, Sood S, Mardi K and Venkat B: Case 231: Retroperitoneal Adrenal Teratoma Presenting as Trichoptysis. Radiology 280: 317-321, 2016.

26. Kataoka M, Fukushima H, Nakanishi Y, Yokoyama M, Funata N, Motoi T, Tobisu KI and Koga F: Retroperitoneal Teratoma in an Adult: A Potential Pitfall in the Differential Diagnosis of Adrenal Myelolipoma. Case Rep Urol 2016: 5141769, 2016.

27. Wang LJ, Chu SH, Ng KF and Wong YC: Adenocarcinomas arising from primary retroperitoneal mature teratomas: CT and MR imaging. Eur Radiol 12: 1546-1549, 2002.

28. Yoon SS, Tanabe KK and Warshaw AL: Adult primary retroperitoneal teratoma. Surgery 137: 663-664, 2005.

29. Jones NM and Kiely EM: Retroperitoneal teratomas--potential for surgical misadventure. J Pediatr Surg 43: 184-186, discussion 187, 2008.

30. James J, Dhillon GS, Blewett CJ, Halldorsson A and Cecalupo AJ: A large adrenal teratoma in a neonate. Am Surg 75: 347-349, 2009.

31. Gagner M, Lacroix A and Bolté E: Laparoscopic adrenalectomy in Cushing's syndrome and pheochromocytoma. N Engl J Med 327: 1033, 1992.

32. Chuan-Yu S, Yat-Faat H, Wei-Hong D, Yuan-Cheng G, Qing-Feng H, Ke X, Bin G and Guo-Wei X: Laparoscopic adrenalectomy for adrenal tumors. Int J Endocrinol 2014: 241854, 2014. 